\title{
Fatigue Life Predictions of Notched Specimen for 022Cr17Ni12Mo2 Stainless Steel
}

\author{
Jingying Tan ${ }^{1, ~ a}$, Qizhou Wü, b, Ran Sun ${ }^{2, b}$ and Dan Jin ${ }^{2, b *}$ \\ ${ }^{1}$ School of Mechanical Engineering, Hunan Institute of Science and Technology, Yueyang, \\ 410000, China; \\ ${ }^{2}$ School of Energy and Power Engineering, Shenyang University of Chemical Technology, \\ Shenyang 110142, China

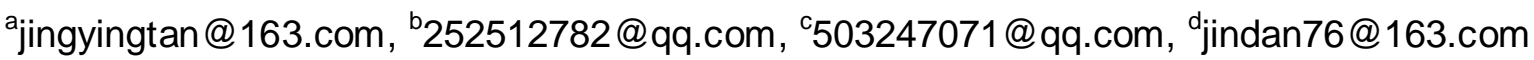

Keywords: 022Cr17Ni12Mo2 stainless steel; Low cycle fatigue; Notched specimen; Fatigue notched factor; Fatigue life prediction

\begin{abstract}
A series of low cycle fatigue tests under stress control were conducted for notched specimen of $022 \mathrm{Cr} 17 \mathrm{Ni} 12 \mathrm{Mo} 2$ stainless steel. The tensile test results show that the yield strength and tensile strength of the notched specimen are more than those of smooth specimen. The necking phenomena indicate that the material has excellent plasticity. The fatigue lives of notched specimens were predicted by the local stress-strain approach. The predictions of fatigue notched factor form tests are more accurate than those of Peterson approach. The predictions of crack initiation life are in a factor-2 scatter band.
\end{abstract}

\section{Introduction}

For practical structure, there would inevitably be discontinuous structure in the keyway, threaded hole, and so on. The fatigue failure would happen due to the obvious stress concentration. The researchers of all over the world have paid more attention to the fatigue failure in the notched specimen. $022 \mathrm{Cr} 17 \mathrm{Ni} 12 \mathrm{Mo} 2$ stainless steel (316L in US) has been used in vessel, petrochemical engineering in the high temperature, corrosion environment, generation-IV nuclear reactors due to better high-temperature strength, work hardening, good plasticity and weldability [1].

Recent years, many researches have been done for this material. Roy et al [2] found that 316L behaved cyclic hardening in the early circulation and the temperature change had a significant influence on the low cycle fatigue performance by the uniaxial cyclic fatigue test and microanalysis. Kim et al [3-4] carried the fatigue tests for this material and concluded that the fatigue life, creep fatigue life, and saturation stress increased with increase in nitrogen content. Puchi-Cabreraa et al [5] conducted the high cycle fatigue tests of $316 \mathrm{~L}$ under constant and variable amplitude loading under axial loading. When failure cycles 144,000-271,000, the yield stress has increased notably. When the stretching stress stabilizing, plastic distortion concentrated at the notch and other mechanical properties have been kept unchanged.

In this investigation, a series of tensile tests and low cycle fatigue tests for stress ratio $\mathrm{R}=0$ under stress control were conducted for notched specimens of $022 \mathrm{Cr} 17 \mathrm{Ni} 12 \mathrm{Mo} 2$ stainless steel. The fatigue lives were predicted based on the damages calculated by Peterson approach and $K_{f}$ based on the test results.

\section{Test Procedure}

Specimen Preparation. Test material used in this study was $022 \mathrm{Cr} 17 \mathrm{Ni} 12 \mathrm{Mo} 2$ stainless steel, cold rolling state. The chemical composition of the material tested is shown in Table 1. The material property are followed, yield strength $342 \mathrm{MPa}$, ultimate strength $607 \mathrm{MPa}$, reduction of area $68 \%$, and elasticity modulus 200GPa. 
Table 1 Chemical composition of 022Cr17Ni12Mo2 stainless steel (wt.\%).

\begin{tabular}{|c|c|c|c|c|c|c|c|c|c|}
\hline $\mathrm{C}$ & $\mathrm{Si}$ & $\mathrm{Mn}$ & $\mathrm{P}$ & $\mathrm{S}$ & $\mathrm{Cr}$ & $\mathrm{Ni}$ & $\mathrm{Cu}$ & $\mathrm{N}$ & $\mathrm{Mo}$ \\
\hline 0.024 & 0.53 & 1.23 & 0.03 & 0.001 & 16.58 & 10.19 & 0.0344 & 0.03 & 2.17 \\
\hline
\end{tabular}

The plate specimens used in low cycle fatigue tests for notched specimen are shown in Fig. 1. The thickness is $1 \mathrm{~mm}$. The semicircle notch was chosen for the tests, $\mathrm{R}=0.25 \mathrm{~mm}$. The elastic stress concentration factors is $K_{T}=2.4$.

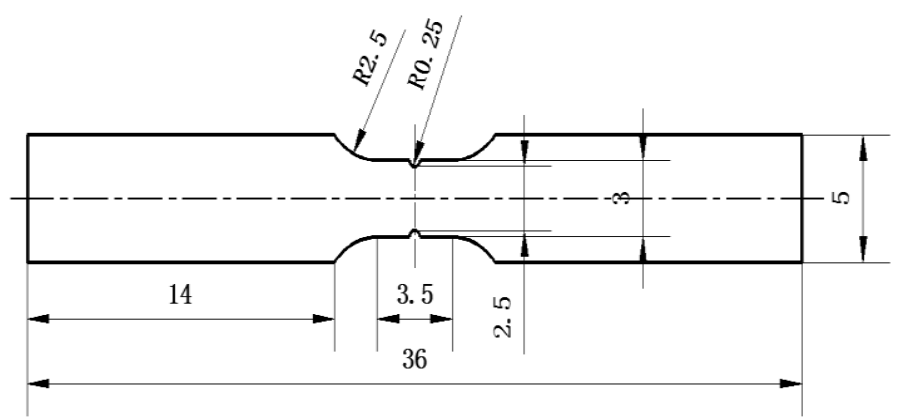

Figure 1. Notched specimen (mm)

\section{Test Process.}

EUT-1020 was used for low cycle fatigue tests under uniaxial loading at room temperature. The tensile tests were carried for notched specimens and the load velocity was $0.8 \times 10^{-3} \mathrm{KN} / \mathrm{s}$. Two groups could be conducted for the smooth and notched specimens respectively and the results were given by the average. The pull-pull fatigue tests were carried under stress control for notched specimens. The waveform was triangular. The minimum load was set zero (i.e., stress ratio $\mathrm{R}=0$ ). The failure life was defined as fracture. The detail test conditions and fatigue test results are shown in Table 2.

Table 2 Test conditions and fatigue test results for notched specimen

\begin{tabular}{|c|c|c|c|}
\hline Serial number & $\mathrm{F}_{\max } / \mathrm{KN}$ & $\sigma_{\max } / \mathrm{MPa}$ & Fatigue life $\left(\mathrm{N}_{\mathrm{f}}\right) /$ cycle \\
\hline No.1 & 1.4 & 564 & 1368 \\
\hline No.2 & 1.3 & 518 & 3240 \\
\hline No.3 & 1.2 & 480 & 5393 \\
\hline No.4 & 1.1 & 442 & 7582 \\
\hline No.5 & 1.0 & 400 & 12338 \\
\hline No.6 & 0.9 & 360 & 19386 \\
\hline No.7 & 0.8 & 320 & 31697 \\
\hline No.8 & 0.7 & 282 & 41868 \\
\hline
\end{tabular}

\section{Discussion on Tensile Tests.}

Two tensile curves of smooth specimen and notched specimen are shown in Fig. 3. The yield strength and tensile strength of smooth specimens are gained from the tensile curve in Fig. 2, $\sigma_{s}=320 \mathrm{MPa}$ and $\sigma_{b}=585 \mathrm{MPa}$ respectively. However, the yield strength and tensile strength of notched specimens are $\sigma_{s}=360 \mathrm{MPa}$ and $\sigma_{b}=632 \mathrm{MPa}$. The values for notched specimen are larger than those of smooth specimen due to the reinforcement notch. At the end of the tensile curves, there are obvious necking phenomena, i.e., stress decreases with increase in strain. It shows that the material possesses the excellent plasticity. 


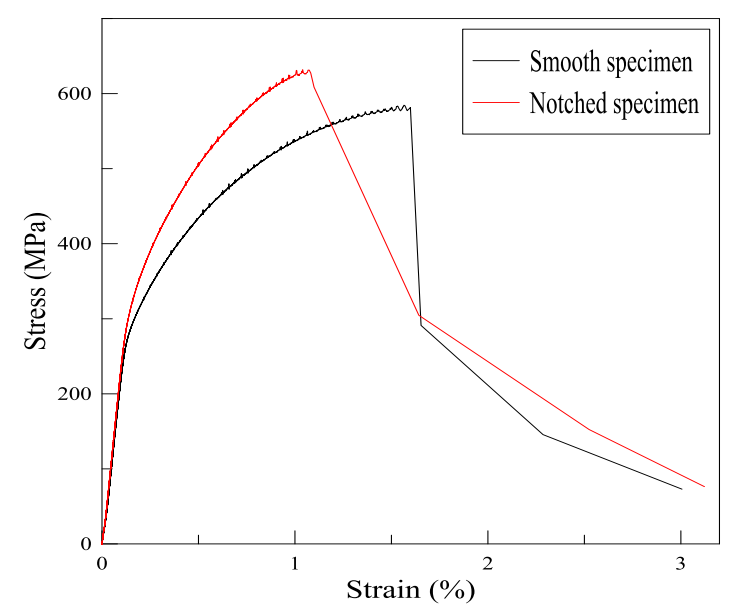

Figure 2. Tensile stress-strain curve

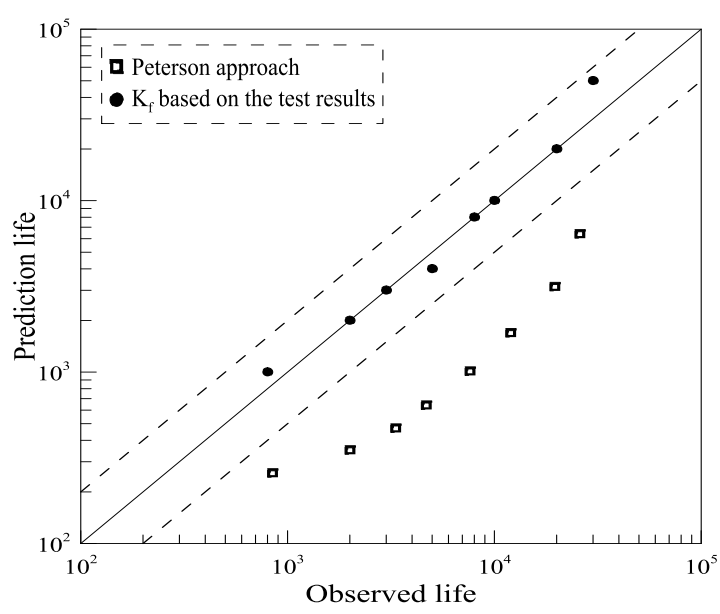

Figure 3. Predictions by different $K_{f}$

\section{Local Stress-Strain Approach}

The local stress-strain approach has been used for the fatigue life prediction for notched specimen. For this approach, the determination of local strain $\varepsilon$ at dangerous point is very important. Neuber rule [6] has be used widely due to its simplicity and it can be written as

$$
K_{T}=\sqrt{K_{\sigma} K_{\varepsilon}}
$$

Where $K_{\sigma}=\Delta \sigma / \Delta S, K_{\varepsilon}=\Delta \varepsilon / \Delta e . \Delta S, \Delta e, \Delta \sigma, \Delta \varepsilon, K_{T}$ are nominal stress, nominal strain, local stress, local strain, and elastic stress concentration factor. Equ.1 can be converted into

$$
\Delta \sigma \Delta \varepsilon=K_{T}^{2} \Delta S^{2} / E
$$

Combination Equ.1 and the constitutive relation

$$
\Delta \varepsilon=\Delta \sigma / E+(\Delta \sigma / K)^{1 / n}
$$

The local stress and strain at the notch root can be gained

$$
(\Delta \sigma)^{2} / 2 E+\Delta \sigma(\Delta \sigma / 2 K)^{1 / n^{\prime}}=\left(K_{T} \Delta S\right)^{2} / 2 E
$$

where $K$ and $n^{\prime}$ are cyclic hardening coefficient and cyclic hardening exponent and they can be gained from the stress-strain curve at half-life. The values are $K=2850$ and $n^{\prime}=0.38$.

The conservative predictions have been gained if the damage was calculated by Neuber rule. So the fatigue notch factor $K_{f}$ was used to calculate the damage instead of the elastic stress concentration factor $K_{T}[7]$. The modified Neuber formula can be written as.

$$
\Delta \sigma \Delta \varepsilon=K_{f}^{2} \Delta S^{2} / E=C
$$

Thus, Equ.4 can be written to

$$
(\Delta \sigma)^{2} / 2 E+\Delta \sigma(\Delta \sigma / 2 K)^{1 / n^{\prime}}=\left(K_{f} \Delta S\right)^{2} / 2 E
$$

\section{Fatigue Life Prediction}

Peterson Approach. Peterson proposed a new formula to determine the fatigue notch factor according to the size effect of statistics[8]: 


$$
K_{f}=1+\left(K_{T}-1\right) /(1+a / R)
$$

Where, $R$ is the radius of the notch, $a$ is a material constant related to the ultimate strength and can be gained from Equ.8.

$$
a=\left(\frac{270}{\sigma_{b}}\right)^{1.8}
$$

Where, $\sigma_{b}$ is the ultimate strength. The fatigue notch factor $K_{f}=1.7$ is obtained according to Peterson approach.

$K_{f}$ based on the test results. The definition of $K_{f}$ is the ratio of the fatigue limit of smooth specimen to the fatigue limit of notched specimen[9]. Combining the $\varepsilon-N$ curve of smooth specimen curve and notched curve, the fatigue notched coefficient $K_{f}=1.2$ is gained and the infinite fatigue life is considered as $10^{5}$.

Fatigue life predictions. The crack initiation life did not be measured during the test process due to the limited the equipment. For this material, the ratio of the initiation life to fatigue failure life is $62 \%$ according to the statistics results on the crack initiation life of notched specimen [10-11]. The damage is calculated based on different $K_{f}$, Peterson approach and $K_{f}$ based on the test results. The predictions are shown in Fig. 3.

It can be seen from the Fig. 3 that the predictions from Peterson approach are conservative. The material behaves the excellent plasticity that can be seen from Fig. 2 and the fatigue life decrease due to the notched effect is not obvious. But the predictions from $K_{f}$ based on the test results are satisfied and most predictions are in a factor-2 scatter band.

\section{Conclusions}

A series of low cycle fatigue tests under stress control were conducted for notched specimen for 022Cr17Ni12Mo2 stainless steel. It can be concluded,

(1) The yield strength and tensile strength of the notched specimen are more than those of smooth specimen in the tensile test. The obvious necking phenomena indicate that the material has excellent plasticity.

(2) For the fatigue life prediction of notched specimens, the predictions of local stress-strain approach which is under fatigue notched factor from tests are more accurate than those of Peterson approach. The predictions of crack initiation life are in a factor- 2 scatter band.

\section{Acknowledgement}

The authors are grateful to the supports of the projects of National Natural Science of Foundation of China (Grant No.11102119) and Hunan Provincial Natural Science Foundation of China (13JJ6067).

\section{References}

[1] S. Bagherifard, S. Slawik, Inés Fernández-Pariente, et al., Nanoscale surface modification of AISI 316L stainless steel by severe shot peening, Mater. Des., 102 (2016)68-77

[2] S.C. Roy, S. Goyal. Low cycle fatigue life prediction of $316 \mathrm{~L}(\mathrm{~N})$ stainless steel based on cyclic elasto-plastic response. Nucl. Eng. Des., 253(2012)219-225.

[3] D.W. Kim, J. H Chang, W. S. Ryu. Evaluation of the creep-fatigue damage mechanism of Type 316L and Type 316LN stainless steel. Int. J. Pres. Ves. Pip., 85(2008)378-384.

[4] J. W. Kim, T. S. Byun. Analysis of tensile deformation and failure in austenitic stainless steels: 
Part I-Temperature dependence. J. Nucl. Mater., 396(2010)1-9.

[5] E. S Puchi-Cabrera, M.H Staia, C. Tovar, et al. High cycle fatigue behavior of 316L stainless steel. Int. J. Fatigue. 30(2008)2140-2146.

[6] H. Neuber. Theory of stress concentration for shear-strained prismatic bodies with arbitrary nonlinear stress-strain law. J. Appl. Mech., 28(1961) 544-550.

[7] T. H Topper, R. M Wetzel, J. Morrow. Neuber's rule applied to fatigue of notched specimens. J. Mater., 4(1969)200-209.

[8] H. O. Fuchs, R. I. Stephens. Metal fatigue in engineering. New York: John Wiley, 1980, pp45-80.

[9] P. Kuhn, H. F Hardraht. An Engineering Method for Estimating the Notch-Size Effect in Fatigue Tests on Steel. NACA TN2805, Washington, 1952.

[10] P. S Song, Y. L Shieh. Stop drilling procedure for fatigue life improvement. Int. J. Fatigue, 26(2004) 1333-1339.

[11] D. Jin, D. J. Tian, W. Wang, et al, Fatigue life predictions of notched specimen under nonproportional loading, Engineering Mechanics, 31(2014)212-221.(in Chinese) 